\title{
QUALIDADE DE CULTIVARES DE ALFACE PRODUZIDOS EM HIDROPONIA ${ }^{1}$
}

\author{
Silvana Ohse ${ }^{2,5}$; Durval Dourado-Neto ${ }^{3,6, *}$; Paulo Augusto Manfron ${ }^{4}$; Osmar Souza dos Santos ${ }^{4}$ \\ ${ }^{2} P$ ós-Graduanda do Depto. de Produção Vegetal - USP/ESALQ. \\ ${ }^{3}$ Depto. de Produção Vegetal - USP/ESALQ, C.P. 9 - CEP: 13418-900 - Piracicaba, SP. \\ ${ }^{4}$ Depto. de Fitotecnia - UFSM - CEP: $97105-900$ - Santa Maria, RS. \\ ${ }^{5}$ Bolsista CAPES. \\ ${ }^{6}$ Bolsista CNPq. \\ *Autor correspondente <dourado@carpa.ciagri.usp.br>
}

RESUMO: O objetivo do presente trabalho foi determinar a composição centesimal de seis cultivares de alface (Aurora, Brisa, Lívia, Mimosa, Regina e Verônica) utilizando quatro soluções nutritivas em Santa Maria, RS. Foi utilizado o delineamento experimental inteiramente casualizado com parcelas subdivididas. $O$ experimento constou de oito bancadas, duas para cada solução nutritiva, sendo que cada bancada continha seis canais, um para cada cultivar. O espaçamento utilizado foi $0,18 \mathrm{~m}$ entre canais e $0,25 \mathrm{~m}$ entre plantas no canal. A solução Ueda, por ter concentração de nutrientes inicial baixa e por essa não ter sido mantida, apresentou maior produção de massa de matéria seca, valor calórico, teores de extrato etéreo e de fibras, depreciando a qualidade do produto final. A alface sob hidroponia (soluções Castellane-Araújo, Furlani e Bernardes) é um alimento altamente saudável por manter ou melhorar sua composição centesimal (teores de proteína, extrato etéreo, fibra e resíduo mineral) quando comparada com a cultivada no solo, e por ser um produto de baixo valor calórico.

Palavras-chave: Lactuca sativa, hidroponia, composição centesimal

\section{QUALITY OF LETTUCE CULTIVARS GROWN IN HYDROPONIC SOLUTION}

\begin{abstract}
The purpose of this research was to define the centesimal composition of six lettuce cultivars (Aurora, Brisa, Lívia, Mimosa, Regina and Verônica) using four nutrient solutions. The experimental design was carried out in Santa Maria, RS, Brazil, consisting of entirely randomized subdivided parcels. The used spacing was $0.18 \mathrm{~m}$ between array and $0.25 \mathrm{~m}$ among plants. It was observed that the Ueda solution should not be used for the lettuce production in NFT system, due to the high dry mass production and, consequently, high caloric value, content of lipids and fibers, depreciating the quality of the final product, in spite of its low nitrate content. The lettuce production in the NFT system using the Castellane-Araújo, Furlani and Bernardes solutions maintained the nutricional quality (protein, ethereal extract and fiber, mineral residue contents) equivalent to the lettuce produced in soil, but presenting smaller caloric value. Therefore, the hydroponic lettuce is a healthy food for maintaining and improving its centesimal composition for being a product of low caloric value, easy cleaning and high durability.

Key words: Lactuca sativa, hydroponic solution, centesimal composition
\end{abstract}

\section{INTRODUÇÃO}

O consumo de hortaliças tem aumentado não só pelo crescente aumento da população, mas também pela tendência de mudança no hábito alimentar do consumidor, tornando-se inevitável o aumento da produção. Por outro lado, o consumidor de hortaliça tem se tornado mais exigente, havendo necessidade de produzi-la em quantidade e qualidade, bem como manter o seu fornecimento o ano todo. Devido a essa tendência do mercado hortícola é que o cultivo protegido (túneis e estufas) vem aumentando a cada ano, assim como o cultivo hidropônico. Esse sistema, apesar de recente no país, tem apresentado um acréscimo no número de usuários, principalmente próximo aos grandes centros consumidores.
A alface (Lactuca Sativa L.)é a planta cultivada em maior escala pela Técnica do NFT (Nutrient Film Technique ou fluxo laminar de solução). Isso se deve à sua fácil adaptação ao sistema, no qual tem revelado alto rendimento e reduções de ciclo em relação ao cultivo no solo. As hortaliças folhosas são recomendadas na dieta alimentar de pessoas em tratamento da obesidade e de doenças crônico-degenerativas (doenças cardiovasculares, diabetes mellitus e câncer) por apresentarem baixo valor calórico, ampliando com isso, seu mercado. A importância da alface na alimentação e saúde humana se destaca por ser fonte de vitaminas e sais minerais, constituindo-se na mais popular dentre aquelas em que as folhas são consumidas. Seu consumo é feito in natura, e nessas condições apresenta a seguinte composição média, por 100 g: água: 94\%; valor calórico: $18 \mathrm{Kcal}$; proteína: 1,3 g;

${ }^{1}$ Parte da Tese de Doutorado da primeira autora apresentada à USP/ESALQ - Piracicaba, SP. 
extrato etéreo: $0,3 \mathrm{~g}$; carboidratos totais: $3,5 \mathrm{~g}$; fibra: 0,7 g; cálcio: $68 \mathrm{mg}$; fósforo: $27 \mathrm{mg}$; ferro: $1,4 \mathrm{mg}$; potássio: $264 \mathrm{mg}$; tiamina: $0,05 \mathrm{mg}$; riboflavina: $0,08 \mathrm{mg}$; niacina: 0,4 mg; vitamina C: $18,0 \mathrm{mg}$, segundo Sgarbieri (1987), para alface produzida no solo.

A produção e o consumo de alface obtida pela técnica do fluxo laminar de solução têm aumentado consideravelmente, devido ao seu melhor aspecto visual, à sua maior durabilidade e à facilidade na limpeza, no entanto, praticamente nada se sabe sobre sua qualidade nutricional. Com essa preocupação, foi desenvolvido o presente trabalho, no qual foram determinados composição centesimal e o valor calórico de seis cultivares de alface produzidas sob quatro soluções nutritivas utilizadas no Brasil.

\section{MATERIAL E MÉTODOS}

O experimento foi conduzido de 5 maio a 13 de julho de 1998, no Núcleo de Pesquisa em Ecofisiologia e Hidroponia do Departamento de Fitotecnia da Universidade Federal de Santa Maria, Santa Maria, RS, situada na região da Depressão Central do Estado, apresentando como coordenadas $53^{\circ} 48^{\prime} 42$ " de longitude oeste e $29^{\circ} 41^{\prime} 25^{\prime \prime}$ de latitude sul, com altitude de 95m.

Os tratamentos constaram da combinação de seis cultivares de alface, sendo três do tipo folha lisa (Aurora, Lívia e Regina) e três do tipo folha crespa (Brisa, Mimosa e Verônica) e quatro soluções nutritivas: Ueda (Ueda, 1990), Furlani (Furlani, 1995), Castellane-Araújo (Castellane \& Araújo, 1995) e Bernardes (Bernardes, 1997), constituindo um fatorial 6x4. A composição química das soluções nutritivas testadas constam na TABELA 1. $O$ delineamento experimental foi o inteiramente casualizado em parcelas subdivididas, com duas repetições e amostragens na subparcela.

A semeadura foi realizada no dia 5 de maio de 1998 em bandejas de poliestireno expandido de 288 células, previamente preenchidas com substrato comercial, colocando-se 1 semente por célula, cobrindo-as com uma fina camada do mesmo. Posteriormente as bandejas foram colocadas para flutuar sobre uma lâmina de aproximadamente $0,05 \mathrm{~m}$ de solução nutritiva CastellaneAraújo diluída a $25 \%$, constituindo uma "piscina". Após permanecerem na piscina até atingirem 4 a 5 folhas e cerca de $0,05 \mathrm{~m}$ de altura, as plantas foram então retiradas da bandeja, tiveram suas raízes lavadas e foram transferidas para o berçário ou bancada temporária, etapa esta de adaptação ao sistema hidropônico que tem por objetivo desenvolver o sistema radicular, utilizando-se solução Castellane-Araújo diluída a 50\%.

O berçário constou de um reservatório contendo 400 litros, armazenando a solução nutritiva, a qual foi recalcada por um conjunto moto-bomba de $0,5 \mathrm{HP}$ para a parte superior da bancada, passando pelos canais de cultivo e recolhida pelo canal coletor retornando ao reservatório. O leito hidropônico constou de telha de fibra de vidro com dimensões de 4,0x2,1 m e profundidade dos
TABELA 1 - Composição química das soluções nutritivas estudadas. Santa Maria, RS, 1998.

\begin{tabular}{lcccc}
\hline \multirow{2}{*}{ Componente } & \multicolumn{4}{c}{ Solução } \\
\cline { 2 - 5 } & Ueda & $\begin{array}{c}\text { Castelane- } \\
\text { Araújo }\end{array}$ & Furlani ${ }^{1}$ & Bernardes \\
\cline { 2 - 5 } $\mathrm{Ca}\left(\mathrm{NO}_{3}\right)_{2} \cdot 6 \mathrm{H}_{2} \mathrm{O}$ & 125 & 950 & 1000 & 1200 \\
$\mathrm{MAP}$ & - & & 150 & - \\
$\mathrm{DAP}$ & 30 & - & - & - \\
$\mathrm{H}_{2} \mathrm{PO}_{4}$ & - & - & - & 150 \\
$\mathrm{KH}_{2} \mathrm{PO}_{4}$ & - & 272 & - & 136,1 \\
$\mathrm{KCl}$ & - & - & 150 & 250 \\
$\mathrm{KNO}_{3}$ & 200 & 900 & 600 & 260 \\
$\mathrm{MgSO}_{4} \cdot 7 \mathrm{H}_{2} \mathrm{O}$ & 60 & 246 & 250 & 500 \\
$\mathrm{MnCl}_{2} \cdot \mathrm{H}_{2} \mathrm{O}$ & - & - & 2,34 & - \\
$\mathrm{MnSO}_{4} \cdot \mathrm{H}_{2} \mathrm{O}$ & 2,00 & 1,70 & - & 1,55 \\
$\mathrm{ZnSO}_{4} \cdot 7 \mathrm{H}_{2} \mathrm{O}$ & 0,05 & 1,15 & 0,88 & 0,22 \\
$\mathrm{CuSO}_{4} \cdot 5 \mathrm{H}_{2} \mathrm{O}$ & 0,03 & 0,19 & 0,20 & 0,08 \\
$\mathrm{H}_{3} \mathrm{BO}_{3}$ & 3,00 & 2,85 & 2,04 & 2,86 \\
$\mathrm{Na}_{2} \mathrm{MoO}_{4} \cdot 2 \mathrm{H}$ & 0,05 & 0,12 & 0,26 & 0,03 \\
$\mathrm{Fe}_{2} \mathrm{EDTA}^{2}$ & $1000 \mathrm{~mL}$ & $1000 \mathrm{~mL}$ & $500 \mathrm{~mL}$ & $1000 \mathrm{~mL}$ \\
\hline
\end{tabular}

${ }^{1}$ Os micronutrientes da solução nutritiva sugerida por Furlani (1995) foram fornecidos na forma de solução concentrada, obtida através da dissolução separada dos sais em $100 \mathrm{~mL}$ de água. Após a dissolução completa dos sais, misturou-se e completou-se o volume para $1000 \mathrm{~mL}$.

${ }^{2}$ Nas soluções sugeridas por Castellane \& Araújo, Furlani e Ueda foi utilizado o Fe-EDTA como fonte de ferro, obtido pela dissolução de $24,1 \mathrm{~g}$ de $\mathrm{FeSO}_{4} \cdot 7 \mathrm{H}_{2} \mathrm{O}$ em $400 \mathrm{ml}$ de água e $25,1 \mathrm{~g}$ de NaEDTA em $400 \mathrm{ml}$ de água quente $\left(80^{\circ} \mathrm{C}\right)$, misturando-se as duas soluções frias, completando o volume para 1 litro e borbulhando ar por 12 horas, no escuro. Para a solução sugerida por Bernardes, procedeuse a mesma operação, utilizando-se no entanto, $24,9 \mathrm{~g}$ de $\mathrm{FeSO}_{4} \cdot 7 \mathrm{H}_{2} \mathrm{O}$ e $26,1 \mathrm{~g}$ de $\mathrm{Na}$-EDTA.

canais de $0,03 \mathrm{~m}$ e o espaçamento entre plantas foi de $0,08 \times 0,08 \mathrm{~m}$, sendo as plantas sustentadas por placas de isopor de 0,02 $\mathrm{m}$ de espessura, com orifícios de 0,03 $\mathrm{m}$ de diâmetro. As mudas foram transferidas no dia 4 de junho para a bancada de produção, onde se desenvolveram até a colheita, a qual foi realizada no dia 13 de julho.

O leito hidropônico da bancada de produção constou de uma telha de cimento-amianto pintada com tinta neutrol (betuminosa), a fim de evitar em contaminações. O espaçamento foi de $0,18 \mathrm{~m}$ entre fileiras e $0,25 \mathrm{~m}$ entre plantas. Para a sustentação das plantas utilizaram-se placas de poliestireno expandido de $0,02 \mathrm{~m}$ de espessura. As soluções nutritivas foram alocadas nas parcelas principais, ou seja nos reservatórios e os cultivares nas subparcelas, ou seja, nos canais das bancadas, cada reservatório alimentava uma bancada, cada bancada possuía seis canais, nos quais casualizaram-se os cultivares de alface, repetido duas vezes. A circulação da solução foi realizada por um conjunto moto-bomba de 0,5 HP e controlada por um 
temporizador, o qual manteve a circulação por 15 minutos a intervalos de 15 minutos durante o dia (das 6:00 as 18:00 horas) e durante à noite permaneceu ligado às 22:00 e 02:00 por 15 minutos (das 18:00 as 6:00 horas), fornecendo um volume de 2,38 litros de solução por planta.

O volume do reservatório foi completado diariamente para a marca de 400 litros com água de poço artesiano. Em seguida efetuaram-se as leituras do $\mathrm{pH}$ e da condutividade elétrica de cada solução nutritiva. $\mathrm{O} \mathrm{pH}$ foi mantido em torno de 6,0 $\pm 0,2$, utilizando-se para sua redução o $\mathrm{H}_{2} \mathrm{SO}_{4} 1 \mathrm{~N}$ e para sua elevação $\mathrm{NaOH} 2 \mathrm{~N}$.

Foram coletadas quatro plantas por canal (amostragem), e após a pesagem, obteve-se a massa de matéria fresca. A amostra integral (todas as folhas) foi submetida a uma pré-secagem em estufa de ventilação forçada a $65^{\circ} \mathrm{C}$ até atingir massa constante, determinandose então, a massa de matéria seca e dessa foi realizada a análise da composição centesimal (teores de água, fibra, proteína, extrato etéreo, resíduo mineral e carboidratos totais) segundo metodologia sugerida pelo Instituto Adolfo Lutz (1985). A determinação do teor de água foi realizada por aquecimento direto, em estufa regulada a $105^{\circ} \mathrm{C} \pm 5^{\circ} \mathrm{C}$, tendo seus dados transformados em arco seno $\sqrt{x / 100}$. O teor de resíduo mineral foi determinado por incineração, deixando-se na mufla à temperatura de $550^{\circ} \mathrm{C}$ até combustão total e obtenção de resíduo mineral uniforme. A determinação do teor de proteínas foi feita pelo método de Kjeldahl, para nitrogênio total, utilizando-se o fator de correção 6,25 para transformar em proteína. A fração extrato etéreo foi determinada em extrator de Soxhlet, utilizando-se éter de petróleo P.A., como solvente. A determinação da fibra foi feita através da amostra desengordurada, passando primeiramente por uma digestão ácida e posteriormente por uma alcalina. O teor de carboidratos totais foi determinada por diferença após a determinação das frações anteriores. O valor calórico foi calculado a partir dos teores da fração protéica, lipídica e glicídica, utilizando-se os coeficientes específicos que levam em consideração o calor de combustão 4,0; 9,0 e $4,0 \mathrm{kcal}$, respectivamente.

\section{RESULTADOS E DISCUSSÃO}

A análise da variância para teor de nitrato, algumas características da composição centesimal (Teor de água, de fibra, de extrato etéreo, de carboidrato total, de proteína, de cinza ou de resíduo mineral) e valor calórico revelou diferenças entre as soluções nutritivas para teores de água $(P<0,01)$, extrato etéreo $(P<0,01)$, carboidratos totais $(P<0,01)$, valor calórico $(P<0,01)$, proteína $(P<0,05)$ e também para a interação entre soluções nutritivas e cultivares para os teores de fibra $(P<0,01)$ e resíduo mineral $(P<0,01)$.

Os cultivares não diferiram quanto ao teor de água da parte aérea, apresentando teor médio de $94,46 \%$ aos 68 dias após a semeadura (TABELA 2). Esse valor foi semelhante aos citados por Oliveira \& Marchine (1998) e Sgarbieri (1987) para alface cultivada no solo, os quais foram 94,85 e $94,0 \%$, respectivamente. Em alface hidropônica Mondin (1996) encontrou teores inferiores, 92,7 e $92,1 \%$ aos 79 e 93 dias após a semeadura, respectivamente. Já Ruschel (1998) aos 47 dias após a semeadura, com 17 dias na bancada de produção, encontrou teor médio de $96,04 \%$. Essa variação no teor de água se deve, provavelmente ao tempo de permanência das plantas de alface na fase final, sendo que, quanto maior esse período maior o acúmulo de massa de matéria seca e, com isso menor o teor de água.

Os cultivares não diferiram também quanto aos teores de extrato etéreo, carboidratos totais, proteína e valor calórico, apresentando por $100 \mathrm{~g}$ comestíveis valores médios de $0,16 \mathrm{~g} ; 1,78 \mathrm{~g} ; 1,31 \mathrm{~g}$ e 13,79 kcal, respectivamente (TABELA 3). Em alface cultivada no solo, Oliveira \& Marchine (1998) citam teores de 0,1 g; 2,7 g; 1,0 g e 13,0 kcal para alface do tipo crespa e $0,2 \mathrm{~g} ; 2,9 \mathrm{~g} ; 1,3 \mathrm{~g}$ e 15,0 kcal para alface do tipo lisa, respectivamente, para teores de extrato etéreo, carboidratos totais, proteína e valor calórico. Os resultados aqui apresentados não revelaram diferenças entre os cultivares de alface do tipo lisa e crespa para teores de extrato etéreo, proteína e valor calórico em favor dos cultivares com folhas lisas, como citam esses autores, apresentando, no entanto, menor teor de carboidratos totais. Sgarbieri (1987) cita para esses componentes os seguintes valores médios: $0,3 \mathrm{~g} ; 3,5 \mathrm{~g} ; 1,3 \mathrm{~g}$ e $18 \mathrm{kcal}$, apresentando superioridade em extrato etéreo, carboidratos totais e valor calórico. Já Martins \& Riella (1993) citam 0,2 g; 2,3 g; 1,2 g e $16 \mathrm{kcal}$ para esses componentes. A alface hidropônica, tanto cultivares do tipo folha lisa quanto os do tipo folha crespa mantém qualidade nutricional semelhante a alface produzido no sistema convencional (solo), revelando ter menor valor calórico, menor teor de extrato etéreo e carboidratos totais, mantendo o mesmo teor de proteínas que a alface de solo.

TABELA 2 - Teores médios de água (TA), massa de matéria seca total (MST), extrato etéreo (EE), proteína $(\mathrm{Pt})$, carboidratos totais $(\mathrm{CT})$ e valor calórico $(\mathrm{VC})$ da parte aérea de seis cultivares de alface produzidos sob hidroponia durante o período de inverno de 1998. Santa Maria, UFSM, RS.

\begin{tabular}{|c|c|c|c|c|c|c|}
\hline Cultivar & $\mathrm{TA}$ & MST & EE & $\mathrm{Pt}$ & CT & VC \\
\hline & --- & & $\mathrm{g} 100 \mathrm{~g}$ & & & $\begin{array}{c}\mathrm{kcal} \\
100 \mathrm{~g}^{-1}\end{array}$ \\
\hline Aurora & 94,7 a & $5,3 \mathrm{a}$ & $0,2 \mathrm{a}$ & $1,2 \mathrm{a}$ & $1,6 \mathrm{a}$ & $12,4 \mathrm{a}$ \\
\hline Brisa & $94,0 \mathrm{a}$ & $6,0 \mathrm{a}$ & $0,2 \mathrm{a}$ & $1,4 \mathrm{a}$ & $2,2 \mathrm{a}$ & $15,7 \mathrm{a}$ \\
\hline Lívia & 94,3 a & $5,7 \mathrm{a}$ & $0,2 \mathrm{a}$ & $1,3 \mathrm{a}$ & $1,8 \mathrm{a}$ & 13,7 a \\
\hline Mimosa & $94,5 \mathrm{a}$ & $5,5 \mathrm{a}$ & $0,2 \mathrm{a}$ & $1,4 \mathrm{a}$ & $1,8 \mathrm{a}$ & 14,1 a \\
\hline Regina & 94,7 a & $5,3 \mathrm{a}$ & $0,2 \mathrm{a}$ & $1,4 \mathrm{a}$ & $1,5 \mathrm{a}$ & $12,8 \mathrm{a}$ \\
\hline Verônica & 94,6 a & $5,4 \mathrm{a}$ & $0,2 \mathrm{a}$ & $1,3 \mathrm{a}$ & $1,8 \mathrm{a}$ & $13,9 \mathrm{a}$ \\
\hline Média & 94,6 & 5,5 & 0,2 & 1,3 & 1,8 & 13,8 \\
\hline CV (\%) & 0,6 & 10,3 & 13,6 & 12,0 & 24,0 & 15,3 \\
\hline
\end{tabular}

${ }^{*}$ Médias de tratamentos seguidas pela mesma letra na coluna, não diferem pelo teste de Tukey a $5 \%$. 
TABELA 3 - Teores médios de água (TA), massa de matéria seca total (MST), extrato etéreo (EE), proteínas $(\mathrm{Pt})$, carboidratos totais (CT) e valor calórico (VC) da parte aérea da alface, obtida em função da solução nutritiva (Ueda, Furlani, CastellaneAraújo e Bernardes). Santa Maria, UFSM, RS, 1998.

\begin{tabular}{|c|c|c|c|c|c|c|}
\hline Solução & TA & MST & EE & $\mathrm{Pt}$ & CT & VC \\
\hline Nutritiva & $----\cdot$ & ---- & $100 \mathrm{~g}^{-1}$ & & & $\begin{array}{l}\mathrm{kcal} \\
100 \mathrm{~g}^{-1}\end{array}$ \\
\hline $\begin{array}{l}\text { Castellane- } \\
\text { Araújo }\end{array}$ & $95,4 \mathrm{a}$ & $4,5 b$ & $0,1 b$ & $1,5 \mathrm{a}$ & $1,2 b$ & $11,9 a b$ \\
\hline Furlani & $95,6 \mathrm{a}$ & $4,4 \mathrm{~b}$ & $0,1 \mathrm{~b}$ & $1,1 \mathrm{a}$ & $1,3 \mathrm{~b}$ & $11,0 \mathrm{~b}$ \\
\hline Bernardes & $95,5 \mathrm{a}$ & $4,5 \mathrm{~b}$ & $0,1 \mathrm{~b}$ & $1,4 \mathrm{a}$ & $1,6 a b$ & $12,7 a b$ \\
\hline Ueda & $91,3 b$ & $8,7 \mathrm{a}$ & $0,2 \mathrm{a}$ & $1,3 \mathrm{a}$ & $3,0 \mathrm{a}$ & $19,6 \mathrm{a}$ \\
\hline Média & 94,5 & 5,5 & 0,2 & 1,3 & 1,8 & 13,8 \\
\hline CV (\%) & 2,6 & 43,7 & 22,6 & 18,0 & 53,1 & 34,2 \\
\hline
\end{tabular}

*Médias de tratamentos seguidas pela mesma letra coluna, não diferem pelo teste de Tukey a $5 \%$.

A solução Ueda apresentou menor teor de água, maior teor de extrato etéreo, maior teor de carboidratos totais, não diferindo da solução Bernardes e maior valor calórico, não diferindo das soluções Castellane-Araújo e Bernardes, mantendo semelhança as demais soluções quanto ao teor de proteína (TABELA 3). As plantas apresentaram aspecto coriáceo, crescimento lento e alta formação de látex, o que pode ser devido a deficiência nutricional múltipla.

Pode-se comparar a inferioridade da concentração de nutrientes recomendada pela solução Ueda com as demais soluções testadas (TABELA 1). Essa solução apresenta concentração de nutrientes muito baixa, o que levou a planta de alface a acumular alto percentual de massa de matéria seca (8,72\%), fazendo com que vários componentes da composição centesimal (fibra, extrato etéreo e valor calórico) aumentassem consideravelmente, principalmente a fibra. A superioridade da solução Ueda se deve ao fato que as frações lipídicas, protéicas, a fibra e resíduo mineral são calculadas em função da massa de matéria seca total e a fração glicídicas pela diferença das anteriores mais o teor de água, bem como o valor calórico é calculado em função das frações protéica, lipídica e glicídica.

As soluções Furlani, Castellane-Araújo e Bernardes não diferiram quanto aos teores de água, extrato etéreo, carboidratos totais, proteína e valor calórico, apresentando em média quando comparadas com a solução Ueda, $4,44 \%$ mais de água, $4,51 \%$ a mais de proteína, $64,78 \%$ a menos de energia; $80 \%$ a menos de extrato etéreo e $117 \%$ a menos de carboidratos totais. A solução Ueda apresentou valores muito discrepantes das demais soluções testadas, levando a planta de alface à aumentar muito seu valor calórico, o que não é desejado em hortaliças folhosas, por serem indicadas na dieta alimentar justamente, devido ao seu baixo valor calórico. Esse resultado pode ser devido a deficiência nutricional generalizada.

Os cultivares estudados acumularam diferentes teores de fibra na parte aérea em função da solução nutritiva utilizada (TABELA 4). A solução Ueda (1990) foi a que apresentou maiores teores de fibra, diferindo significativamente $(\mathrm{a}=5 \%)$ das demais para os cultivares Aurora, Brisa e Lívia, diferindo também da solução Bernardes para o cultivar Regina. Os valores médios encontrados para cada solução foram 0,$88 ; 0,83 ; 0,73$ e

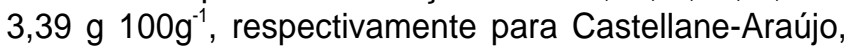
Furlani, Bernardes e Ueda. O alto teor encontrado na solução Ueda se deve ao alto acúmulo de massa de matéria seca, devido a sua baixa concentração de sais e também ao seu crescimento reduzido. Oliveira (1998) e Sgarbieri (1987) citam 0,6 e 0,7 g 100 g $\mathrm{g}^{-1}$ como teores médios para alface produzidas no solo. Percebe-se que a alface hidropônica tende a ter maior teor de fibra que a produzida no solo, isso se deve, provavelmente ao aumento no tamanho das folhas quando produzidas por esse sistema em casa-de-vegetação.

Os cultivares de alface acumularam diferentes teores de resíduo mineral em função do tipo de solução nutritiva utilizada. A solução Furlani apresentou os maiores valores para os cultivares Aurora, Brisa, Mimosa e Verônica, não diferindo da solução Castellane-Araújo para os cultivares Lívia, Mimosa e Regina e, não diferindo da solução Bernardes e Ueda para os cultivares Lívia e Regina (TABELA 5).

O maior teor de resíduo mineral encontrado foi

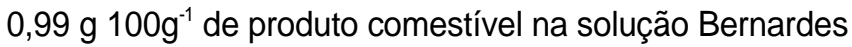
pelos cultivares Mimosa e Verônica e o menor teor foi 0,59 g $100 \mathrm{~g}^{-1}$ na solução Ueda pelo cultivar Brisa, sendo que na média geral não houve diferença significativa entre as solução estudadas.

TABELA 4 - Teor médio de fibra de plantas de alface por cultivar produzidas sob quatro soluções nutritivas (Ueda, Furlani, Castellane-Araújo e Bernardes). Santa Maria, UFSM, RS, 1998.

\begin{tabular}{lcccc}
\hline \multirow{2}{*}{ Cultivar } & \multicolumn{5}{c}{ Solução } \\
\cline { 2 - 5 } & Ueda & $\begin{array}{c}\text { Castellane- } \\
\text { Araújo }\end{array}$ & Furlani & Bernardes \\
\hline AURORA & $4,0 \mathrm{a}$ & $0,8 \mathrm{~b}$ & $0,8 \mathrm{~b}$ & $0,7 \mathrm{~b}$ \\
BRISA & $3,7 \mathrm{a}$ & $0,9 \mathrm{~b}$ & $0,8 \mathrm{~b}$ & $0,7 \mathrm{~b}$ \\
LíVIA & $4,1 \mathrm{a}$ & $0,9 \mathrm{~b}$ & $0,7 \mathrm{~b}$ & $0,6 \mathrm{~b}$ \\
MIMOSA & $2,8 \mathrm{a}$ & $0,9 \mathrm{a}$ & $0,8 \mathrm{a}$ & $0,7 \mathrm{a}$ \\
REGINA & $3,0 \mathrm{a}$ & $0,9 \mathrm{ab}$ & $0,9 \mathrm{ab}$ & $0,8 \mathrm{~b}$ \\
VERÔNICA & $2,7 \mathrm{a}$ & $0,9 \mathrm{a}$ & $0,9 \mathrm{a}$ & $0,7 \mathrm{a}$ \\
\hline MÉDIA & $3,4 \mathrm{a}$ & $0,9 \mathrm{~b}$ & $0,8 \mathrm{~b}$ & $0,7 \mathrm{~b}$ \\
\hline
\end{tabular}

*Médias de tratamentos seguidas pela mesma letra na linha, dentro de cada cultivar, não diferem pelo teste de Tukey a $5 \%$. $\mathrm{CV}=17,6 \%$. 
TABELA 5 - Teor médio de resíduo mineral de plantas de alface por cultivar produzidas sob quatro soluções nutritivas (Ueda, Furlani, Castellane-Araújo e Bernardes). Santa Maria, RS, 1998.

\begin{tabular}{lcccc}
\hline Cultivar & \multicolumn{4}{c}{ Solução } \\
\cline { 2 - 5 } & Ueda & Castellane-Araújo & Furlani & Bernardes \\
\hline & $0,7 \mathrm{ab}$ & $0,6 \mathrm{~b}$ & $0,9 \mathrm{a}$ & $0,8 \mathrm{ab}$ \\
Aurora & $0,6 \mathrm{~b}$ & $0,7 \mathrm{~b}$ & $1,0 \mathrm{a}$ & $0,8 \mathrm{ab}$ \\
Brisa & $0,7 \mathrm{a}$ & $0,9 \mathrm{a}$ & $0,9 \mathrm{a}$ & $0,8 \mathrm{a}$ \\
Lívia & $0,7 \mathrm{~b}$ & $0,9 \mathrm{a}$ & $1,0 \mathrm{a}$ & $0,9 \mathrm{ab}$ \\
Mimosa & $1,0 \mathrm{a}$ & $0,9 \mathrm{a}$ & $0,9 \mathrm{a}$ & $0,8 \mathrm{a}$ \\
Regina & $0,7 \mathrm{~b}$ & $0,9 \mathrm{ab}$ & $1,0 \mathrm{a}$ & $0,8 \mathrm{~b}$ \\
Verônica & $0,7 \mathrm{a}$ & $0,8 \mathrm{a}$ & $0,9 \mathrm{a}$ & $0,8 \mathrm{a}$ \\
\hline Média & & &
\end{tabular}

*Médias de tratamentos seguidas pela mesma letra na linha, dentro de cada cultivar, não diferem pelo teste de Tukey a $5 \%$. $\mathrm{CV}=7,6 \%$.

\section{CONCLUSÕES}

A solução Ueda não deve ser utilizada para a produção de alface no sistema NFT, por aumentar em demasia a produção de massa de matéria seca e, com isso, o valor calórico, teor de extrato etéreo e o teor de fibras, depreciando a qualidade do produto final. Essa solução levou as plantas de alface a apresentarem sintomas de deficiência nutricional múltipla.

Pode-se utilizar para a produção de alface no sistema NFT uma ou outra dessas soluções: CastellaneAraújo, Furlani ou Bernardes, uma vez que mantiveram a qualidade nutricional semelhante a alface produzida no solo para os parâmetros teor de proteína, extrato etéreo, fibra e resíduo mineral, apresentando menor valor calórico, o que é de fundamental importância para pessoas em dieta. A alface hidropônica é um alimento altamente saudável por manter ou melhorar sua composição centesimal quando comparada com a cultivada no solo, por ser um produto de baixo valor calórico.

\section{REFERÊNCIAS BIBLIOGRÁFICAS}

BERNARDES, L.J.H. Hidroponia da alface: uma história de sucesso. São Paulo: Estação Experimental de Hidroponia "Alface e Cia", 1997. 135p.

CASTELLANE, P.D.; ARAÚJO, J.A.C. de. Cultivo sem solo: hidroponia. 4.ed. Jaboticabal: FUNEP, 1995. 43p.
FURLANI, P.R. Cultivo de alface pela técnica de hidroponia NFT. Campinas: IAC, 1995. 18p. (Documentos, 55).

INSTITUTO ADOLFO LUTZ. Normas analíticas do Instituto Adolfo Lutz. 3.ed. São Paulo, 1985.

MARTINS, C.; RIELLA, M.C. Composição e valor nutritivo dos alimentos. In: RIELLA, M.C. Suporte nutricional parenteral e enteral. 2.ed. Rio de Janeiro: Guanabara Koogan, 1993. p.416-431.

MONDIN, M. Efeito de sistema de cultivo na produtividade e acúmulo de nitrato em cultivares de alface. Jaboticabal, 1996. 88p. Tese (Doutorado) - Universidade Estadual Paulista.

OLIVEIRA, J.E.D. de; MARCHINE, J.S. Ciências nutricionais. São Paulo: Sarvier, 1998. 403p.

RUSCHEL, J. Acúmulo de nitrato, absorção de nutrientes e produção de duas cultivares de alface cultivadas em hidroponia, em função de doses conjuntas de nitrogênio e potássio. Piracicaba, 1998. 76p. Dissertação (Mestrado) Escola Superior de Agricultura "Luiz de Queiroz", Universidade de São Paulo.

SGARBIERI, V.C. Alimentação e nutrição: fator de saúde e desenvolvimento. Campinas: UNICAMP, 1987. 387p.

UEDA, S. Hidroponia: guia prático. São Paulo: Agrocasa-deVegetação, 1990. 50p.

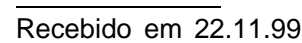

